\title{
Influencing Urban Mobility Through Public Engagement Process: Traditional and Digital Methods for Public Participation in Urban Design
}

\author{
Anja Jutraž and Tadeja Zupančič
}

Faculty of Architecture, University of Ljubljana, Slovenia

\begin{abstract}
The purpose of this article is to show how we can influence urban mobility through public participation. On the one hand, this article focuses on exploring opinions of the public and professionals' opinions regarding public participation (willingness to be involved, when and where they want to be involved etc.), and, on the other hand, it also deals with exploring traditional and digital methods and tools for public engagement (urban experiments, urban interventions, Virtual World Terf). More specifically, it focuses on exploring the role of users in urban mobility. Quantitative and qualitative research methods have been used for the purposes of this article (case study, survey and semi-structured interviews). The final part of this article offers guidelines for future development of methods and tools for public engagement, especially concerning the Terf Virtual World.
\end{abstract}

Keywords: Urban mobility, public engagement, urban design, urban interventions, digital tools, Virtual World Terf.

\section{INTRODUCTION}

According to the European Commission [1], a large majority of European citizens live in an urban environment, they live their daily lives in the same space, and they share the same infrastructure for the purposes of their mobility. The exchange of knowledge and experiences from different cities is necessary in order to promote sustainable urban mobility. The main aim is to reduce the traffic (number of cars and $\mathrm{CO}_{2}$ emission), promote walking and cycling, and consequently pedestrian and cyclist safety, as well as to promote the exchange of experience where an exchange of best practices can help improve the safety of vulnerable road users in urban areas [2]. According to the Arthur D. Little consultancy, a leader in linking strategy, technology and innovation, and UITP, the International Association of Public Transport, an international network for public transport authorities and operators, policy decision-makers, scientific institutes and the public transport supply and service industry, "the headline goal of any effective urban mobility strategy is to satisfy the travel needs of both people and businesses in such a way that it improves quality of life for the citizen and increases the competitiveness of a country or region". Potentially relevant urban mobility solutions should be identified, discussed and assessed by involving both the public and professionals [3].

Tsay and Herrmann [4] discussed sustainable policies for the century of the city, rethinking urban mobility. They said that when producing a local mobility plan, the public engagement in the planning process should be stimulated and

*Address correspondence to this author at the University in Ljubljana, Faculty of Architecture, Zoisova 12, 1000 Ljubljana, Slovenia,

Tel: +386 41632 752; E-mail: anja.jutraz@fa.uni-lj.si the need for multiple parties and stakeholders to work together reinforced. A platform to discuss environmental, social, and economic outcomes should be created. Engaging the public is important because their daily routines and ways of life influence the changes in the built environment. Members from the profession should inform them about the intention, purpose, and the phases of individual projects. Public participation is valuable, as it can "provide detailed knowledge that only locals would be able to offer and it can even inform how project phases are developed" [4].

European cities are moving towards integrated urban mobility approaches. If we compare the traditional transport plans and sustainable urban mobility plans, we can notice that local community involvement is important in sustainable urban mobility plans, with a focus on the participatory approach [5]. Moreover walking and "alternative transportation modes" will bring more people out onto the streets, and it will allow these spaces "to serve as public forums where neighbors and friends can connect with one another" [5].

As Gehl states [6], buildings are usually designed first, then outside space and lastly life is brought to the spaces. Nowadays the spaces should be defined in a different way: first the future users should be identified, then their needs; so "first life, then spaces, then building" [6]. Also Diébédo Francis Kéré said that "people are the basis of every piece of work" [7], and people, i.e. users of public spaces, are also the focus of this paper, as well as their engagement in urban design process, and the latter's influence on urban mobility. It is necessary to involve as many different experts and people who will eventually use the designed urban space [8] as possible. When designing urban spaces, we should not forget their users who give life to urban areas and contribute to their final look. Public engagement could also be seen as an educational process, and through involvement in the 
planning process and by raising awareness, we can influence users' lives. With high quality urban design, we can influence the quality of life and the use of urban space, the quality of living conditions and people's opinions [9]. Public engagement is vital to the city's aims, as this ensures that the needs of a community are fully understood [10].

In this new era, when smart technology is rapidly changing our environment, urban mobility is also changing a lot. Innovative operational and information technologies are being used, and citizens and city infrastructure generate reliable real-time data. According to Buscher, Doody, Webb and Aoun [11] a smart city is "an efficient city, a livable city, as well as an economically, socially and environmentally sustainable city". We can note a need change in cities so that they can become more efficient, attractive, inclusive and competitive. Urban mobility will be changed, and also the ways how cities, businesses, citizens and academia think and work together. This paper explores how we will move from a traditional approach to public engagement to a more advanced one, to digital tools, more specifically, virtual worlds, as an interface for influencing urban mobility. Moreover, "the technologies that enable smarter mobility have a range of capabilities that benefit travelers, service providers and urban planners alike" [11]. Using visualization techniques and tools for enhancing public participation is vital in creating smart cities $[12,13]$. In this paper we will discuss different traditional and digital methods for public participation in urban design, their role and their potentials.

\section{URBAN INTERVENTIONS FOR PROMOTING UR- BAN MOBILITY}

Urban interventions are an innovative way of involving public into urban redesign processes where the urban space is changed through real-time actions. Users are temporarily engaged in the use of urban space, sometimes also in designing it. Actually, we could define urban interventions as an experiment for testing urban space to see what are its limitations and opportunities, and what happens if the design, urban equipment or program is different (whether the public will use urban space in a different way or not). Temporary urban interventions have already been seen in different countries, and its influence on the urban space was always noticeable $[14,15]$. They also might have a great potential for future urban development [16]. For example, Stevens and Ambler [17] consider temporary city beaches as a "tool to optimize the use of a particular spatial resource before the next cycle of large-scale reinvestments, if it ever materializes". Temporary use is defined as a "secondary to functions that could be established to the site later on" [18]. Nevertheless, we could influence urban mobility by temporary urban interventions, as people stop and start using urban space also as places and not only as transition space. Movement from one location to another is transformed to a space for gathering where people come together, where the life of city is concentrated [19].

Different examples have already been noticed of urban interventions, which changed the motion in an urban space or helped change it by creating a sense of community. One of these examples is also the project "Dancing traffic light" in Portugal [20] where the safety in the city was influenced by traffic light installations that entertain waiting pedestrians. People were engaged in creating the dancing traffic light: some people were invited to step into the box where the music was played, and dance there, and the others saw the transformed dancing figure on the nearby traffic light. Consequently, passers-by stopped at the pedestrian crossing when there was a red sign, a dancing figure. It should be clarified here that people would tend to cross the street despite the red light, but with this new installation people actually wait for the green signal to cross, the intersection is therefore safer and more playful. With this urban intervention people's behaviors were influenced, as well as their notion of using urban spaces, so it also had educational purposes. Moreover, many cities have been transforming their streets into pedestrian zones, and spaces used for parking lots are slowly transformed into public spaces (e.g. Ljubljana Slovenska cesta street, Vienna - Maria Hilfer Strasse, New York - Pearl Street Triangle etc.). For example, in the last few years, New York's Department of Transportation has changed a couple of parking sites and streets into public spaces (e.g. Pearl Street Triangle in Dumbo, Brooklyn). Remaking the urban space by placing there some potted trees and chairs had also affected public safety. People use the place all the time, and consequently this area is under supervision at all times and thus provides safety. Moreover, they added new bike lanes, which help connect these new public spaces, NYC is slowly becoming a great public space, and the urban mobility has been changing [21-23]. Whyte [19] said that the street "is the river of life of the city, the place where we come together, the pathway to the center".

In addition to the permanent intervention (New York City DOT project), temporary urban interventions are used as a method of testing urban space, and they can lead to more permanent solutions. For example, in 2010 an interdisciplinary summer workshop was organized in Kamnik, a small town near Ljubljana, where students were asked to design urban spaces for the town's festival. As part of this project, the street regulation was changed for the period of the festival: a two-way street was transformed into a oneway street and half of the street was intended for the public Fig. (1). The project of designing the festival and the town's urban space (by placing homemade urban equipment like branches, tree pots, made from recycled elements) was actually an urban experiment, where the town tested new usage of urban spaces and at the same time tried to draw attention to this space by using temporary urban interventions. With new traffic regulations they wanted to encourage pedestrians and cyclists to use it. This urban test leads to a permanent transformation of the system of transport, bike routes and pedestrian zones: from April 2013 onwards, the street became a one-way street and part of the street is also intended for bikes and pedestrians [24].

\section{DIGITAL TOOLS FOR PROMOTING URBAN MO- BILITY}

Due to the rapid development of digital media in the last decade, physical participation ("face-to-face collaboration") has begun to lose its exclusive role that is slowly being 

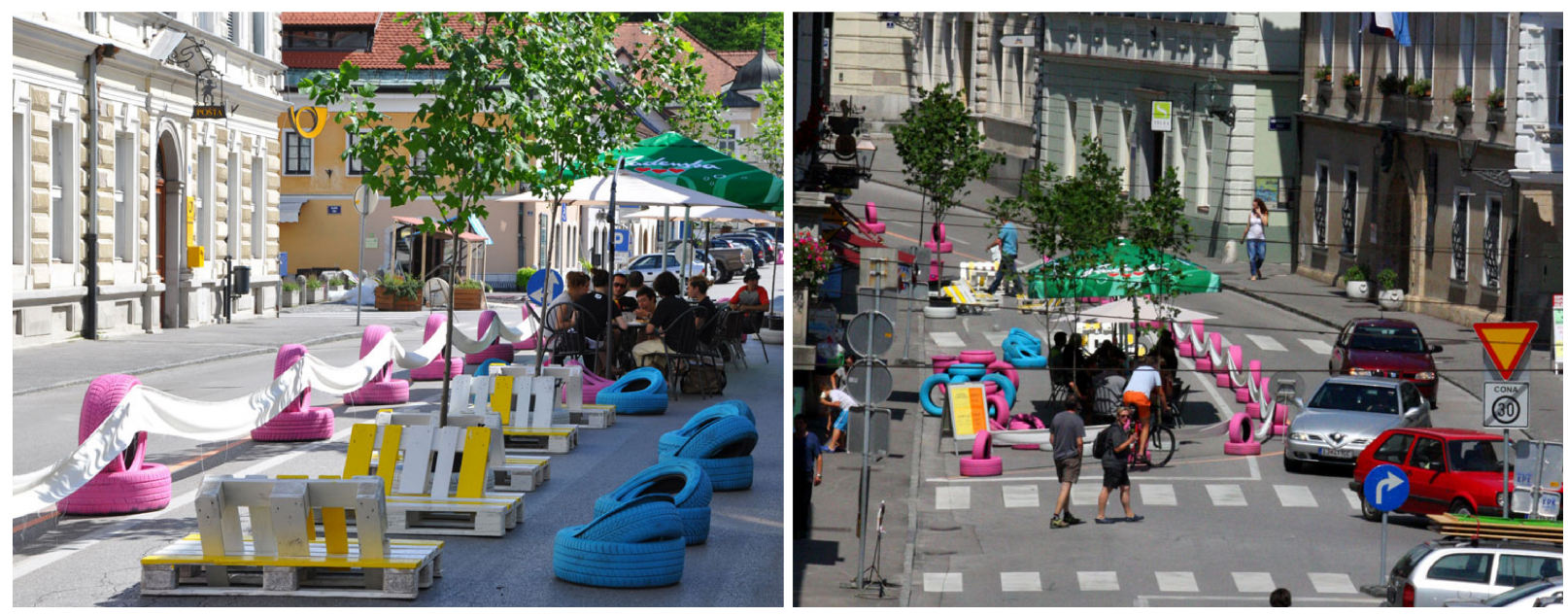

Fig. (1). Urban experiment intended for promotion of urban mobility, Kamfest 2010 (photo: Nadja Hribar).

passed on to increased virtual collaboration $[25,26]$. The paper additionally focuses on exploring new media and digital tools for public engagement [27]. More specifically, it deals with exploring the potential of using virtual worlds in urban design from the first stages of the design process (problem definition) to the construction and maintenance phases $[28,29]$. Our research is based on the virtual world Terf [30], an immersive world that offers users different collaboration tools and at the same time the experience of the future urban site (walk-throughs through the 3D model of the proposed urban redesign with your avatar). Terf is virtually based, without time and location constrains, it can be combined with traditional ways of communication, and it enables you to experience 3D models of neighborhoods from the point of view of pedestrians.

\section{PROBLEM DEFINITION}

The main problem discussed in this article is the lack of urban mobility in open public spaces (streets, neighborhoods etc.). More exactly, we divided the problem into three topics: (1) lack of program, urban equipment and users in the urban space; (2) lack of public engagement from the early stages of urban design process onwards; and (3) lack of appropriate digital tools for public participation processes.

To solve a general problem, a specific location with its specific characteristics and problems was chosen: Bratovševa ploščad platform, a public space in one of Ljubljana's neighborhoods. The platform is basically a public space in one of Ljubljana's suburban neighborhoods, which currently lacks a detailed program concerning the use of this urban space, as well as actual users. The public space at Bratovševa ploščad platform area lacks life, people do not want to spend time there, the space does not offer enough programs, and it is not suitably equipped. Since the public space is located in the heart of a residential neighborhood, it would be highly advisable to ask the people for their wishes and needs.

The main research question of this paper is as follows: Can the public engagement process influence urban mobility (and bring more users to public spaces) by using different traditional and digital methods?

\section{METHODOLOGY}

As a case study Bratovševa ploščad platform, a neighborhood in Ljubljana, was chosen. Our research was divided into three stages where different research methods were used: (1) exploring traditional methods for public participation process (urban experiment; observation and short interviews with people involved in urban activities); (2) exploring the opinions of the public and the opinions of professionals regarding public participation processes in urban design (quantitative research methods, survey); (3) exploring digital tools for the public participation process, with the focus on virtual world Terf (qualitative research methods, semistructured interviews). The main aim was to find out how urban mobility could be influenced and changed through involving the public in urban design (through different activities and by using different tools).

Firstly, we prepared different urban activities in the Bratovševa ploščad platform area and observed the users (during the activities and after). Moreover, we interviewed the participants and discussed with them the problems and possibilities related to the chosen site. We organized the following urban activities: a workshop with kids ("What do you want to see on this urban site?" Children drew pictures.), an urban installation (making urban equipment from recycled materials) and a movie night (projection of a movie on the façade of the apartment building). The urban experiment was done in summer 2013, and except for urban installation, which remained there for a longer period, the urban activities were one-day activities (Fig. 2).

Secondly, the survey was conducted between representatives of the public and experts $(\mathrm{N}=878)$ and it focused on respondents' opinions concerning public participation in urban space. The importance of involving public in an urban design process from the early stages of the design process was discussed, and also the willingness of the public and professionals to take part in public participation activities. We also asked them questions about the time they wanted to devote to public participation, and about the type of projects they wish to have a say in. The survey was prepared as a web interface, and we ensured that respondents were of different 

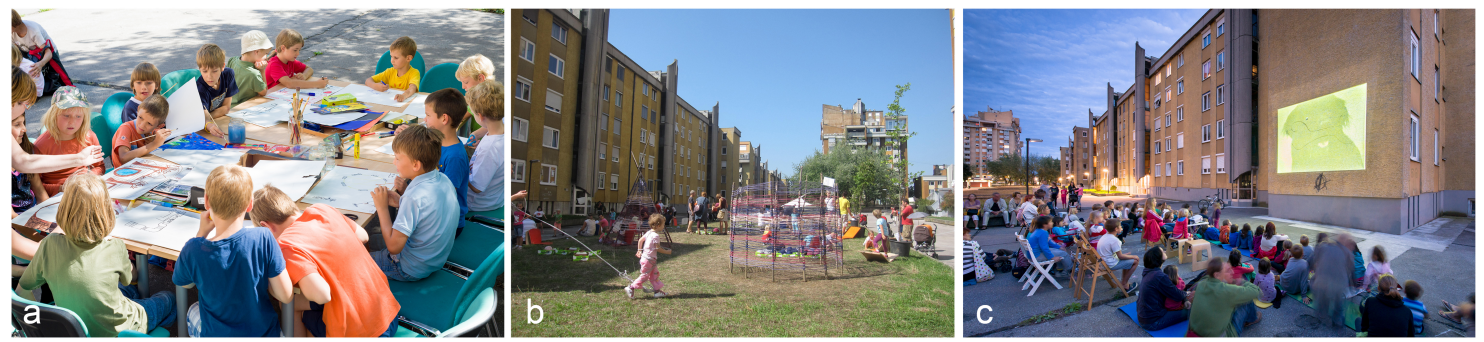

Fig. (2). Urban experiment at Bratovševa ploščad platform, summer 2013 (a - workshop with kids; b - urban interventions; c - movie night in the public space) (photo: Blaž Jamšek).

ages, had different educational backgrounds and came from different professions.

Thirdly, there were semi-structured interviews conducted among representatives of the public and profession $(\mathrm{N}=20)$. They focused on exploring the usability and appropriateness of the Immersive Terf Software, a virtual world, a system of support tools for public engagement in urban design [30]. The virtual world Terf was evaluated by the interviewees themselves, while we also evaluated its appropriateness through observation of the interviewees (how they were using the tool, how they were able to navigate through it, how they rated the experience).

\section{RESULTS}

The results gained through observation (urban experiment, urban activities) will be presented first, then the results of the quantitative research (survey), and last but not least the results of the qualitative research (semi-structured interviews).

\section{(a) The Urban Experiment}

The urban experiment was done at Bratovševa ploščad platform in summer 2013 and it was composed of three main activities: (a) a workshop with kids; (b) urban interventions; (c) a movie night. First, we invited kids and their parents to join us at Bratovševa plaoščad platform, we walked them through the real-life site and pointed out the problems and challenges. We also discussed with them how we could use the public site in a different way, and then we asked them to draw their ideas. Sometimes they did not have realistic ideas (swimming pool, houses on the trees, racing polygon), but at other times their ideas were out of the box and helped us with our future work. The main goal was achieved: kids and their parents started thinking about empty and unusable public space in a different way. The second urban activity was on a larger scale and lasted longer. We invited neighbors to build alongside professionals, thus producing urban equipment for Bratovševa ploščad platform. The workshop was intergenerational and three different generations participated in it: kids, their parents and their grandparents. Together, they designed and built benches, tents, a playground; and the previously empty public space in the neighborhood became livelier at least for a day. We also observed the space after the activity and noticed that urban mobility had changed: more people walked by and more people also stopped there. A movie night was our third event, which involved a projection of a movie on the façade of the building. By bringing back the history (the movie took place in this neighborhood more than 20 years ago), we wanted to show the residents how the public space was used when it was built. During this third activity there were more people present than during the first one (not only the kids), people were talking to each other, and most likely, a community was being built right there and then.

By interviewing residents during different urban activities and asking them what they thought about the space, we discovered they were missing certain urban elements, a program, events, and that they were happy to meet their neighbors, but did not have that many opportunities to do so. Most of them cared about their living environment, but they did not have enough time to organizing events or to maintain it. If there were events or if the space were equipped, they would spend much more time there and they would walk through it on their way to the public transport instead of using only the car. We noticed that public participation activities at an early stage of the design process could have a big influence on urban mobility (Fig. 3).

\section{(b) Survey}

The survey was conducted among 878 people: a total of 674 members of the public whose education, profession or occupation were not related to urban planning and design, as well as 231 representatives of the profession who were professionally, directly or indirectly, involved in designing urban space, and their education, profession or occupation were indeed connected to urban planning disciplines. The survey was done as part of the doctoral thesis "Visual Digital System of Tools for Public Participation in Urban Design", author Anja Jutraž, Prof. Dr. Tadeja Zupančič, mentor [31]. The resulting statistical analyses are based on a comparison of the two sample groups, the public and members of the profession.

Below you can see a detailed look at the desires of the public and professionals expressed through participation and co-decision, judging by the number of alternative proposals they wished would get examined, by the decision-making process, and the amount of time they were willing to spend on this. We wanted to gain insight into the attitudes of 


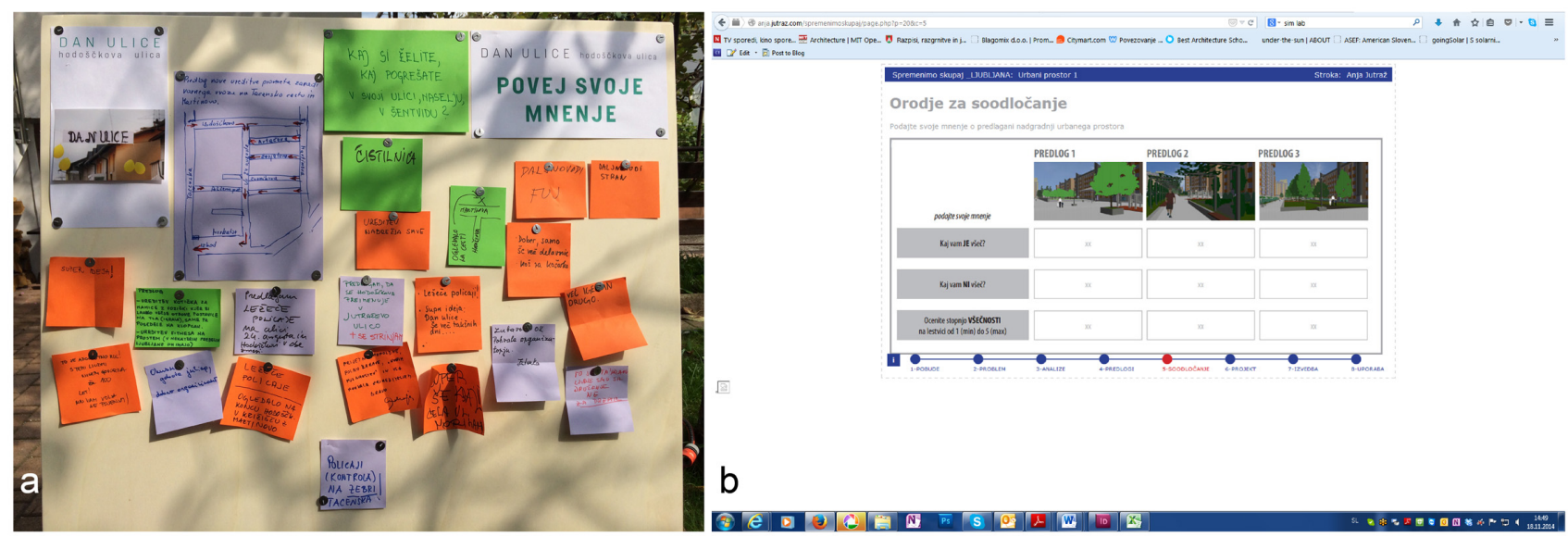

Fig. (3). Public participation in urban design (a - traditional methods: street day 2014; b - digital methods: web page Change Together) (photo: Anja Jutraž).

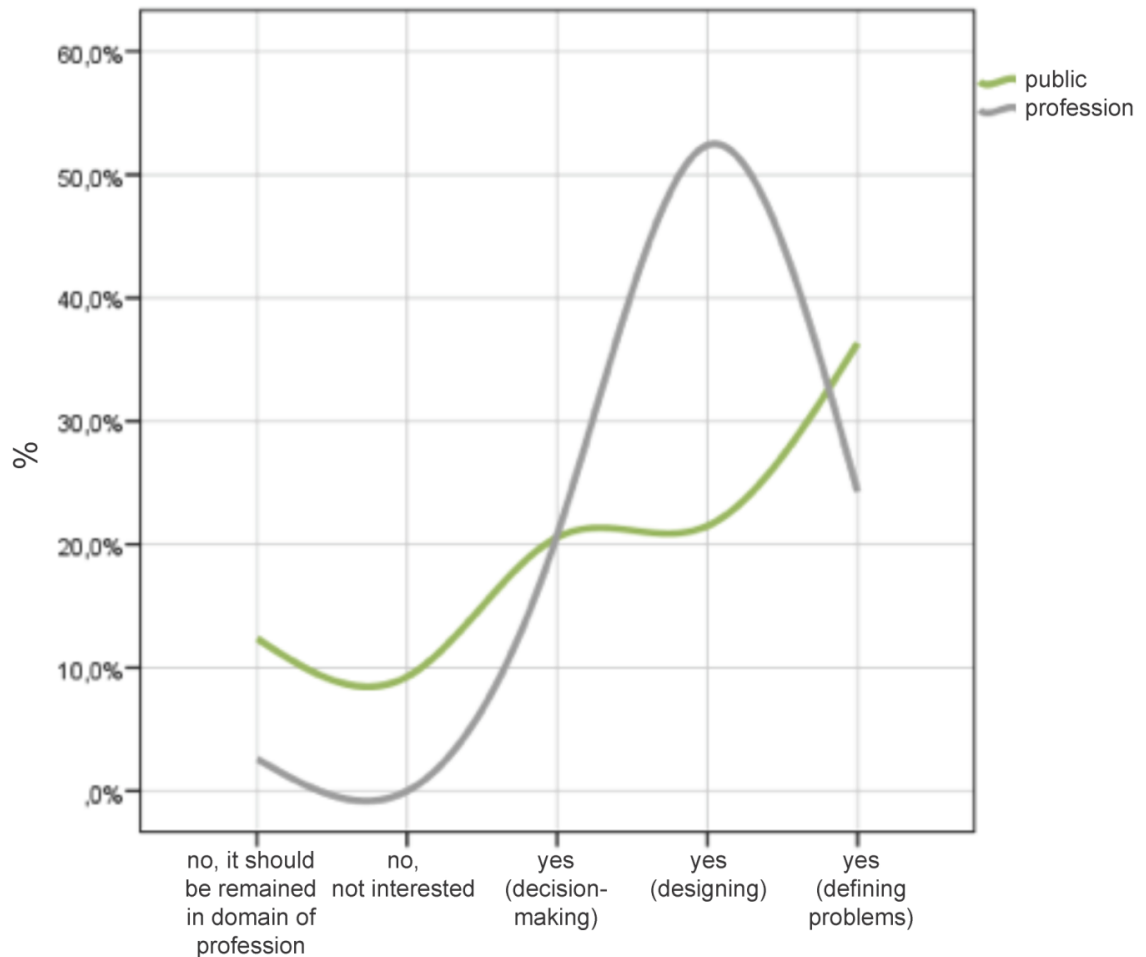

Graph 1. Comparision of the sentiments of professionals and the public, and their desired role in the design and planning of public spaces in their neighborhood.

the public and the members of the profession about participation, and figure out ways in which successful collaboration would be possible (through digital media, physical contact or no desire for collaboration). The desire for the role in designing of public spaces is stronger for the members of the profession than for the public. Professionals want to have a large role in shaping a shared vision of public space $(52.4 \%$ of all respondents were representatives of the profession), and above all, the public wants to express complaints and point out the problems in this urban space (36.6\%). About $20 \%$ of professionals and members of the public want to be involved by deciding on the most appropriate proposal that would be prepared by qualified professionals.
By asking professionals and the public about their role in the designing public spaces (» Would you like to be involved in the design/planning of public spaces in your neighborhood?«), we discovered that on average professionals wanted to be involved in urban redesign process more than public (professionals 3,60 and the public 3,96, where the lower number means that they wanted to be more involved) Graph 1.

It is understood that professionals want to have a role in shaping public spaces near one's home, but there is a surprisingly high percentage of the public wanting to be involved in defining the problem, developing the design, and participating in the decision-making process. 
Table 1. The desire of the public and professionals to participate in co-decision and co-design in urban design processes (in public spaces), expressed in percentages.

\begin{tabular}{|c|c|c|c|}
\hline & & Public & Profession \\
\hline \multirow{3}{*}{ Possibility of co-decision } & yes & $85.6 \%$ & $97.0 \%$ \\
\hline & no & $14.4 \%$ & $3.0 \%$ \\
\hline & average $(0=$ no, $1=$ yes $)$ & 0.86 & 0.97 \\
\hline \multirow{3}{*}{ Possibility of co-designing } & yes & $27.7 \%$ & $96.5 \%$ \\
\hline & no & $72.3 \%$ & $3.5 \%$ \\
\hline & average $(0=$ no, $1=$ yes $)$ & 0.28 & 0.97 \\
\hline
\end{tabular}

Table 2. When, where and how long you would like to participate in the urban design process (in designing public space).

\begin{tabular}{|c|c|c|c|}
\hline & & Public & Profession \\
\hline \multirow{7}{*}{ Participation (when, where) } & never & $11.9 \%$ & $0.9 \%$ \\
\hline & near my home & $18.2 \%$ & $4,8 \%$ \\
\hline & $2 \mathrm{~km}$ away from my home & $6.3 \%$ & $4.8 \%$ \\
\hline & in the city & $47.9 \%$ & $27.3 \%$ \\
\hline & in the region & $8.7 \%$ & $15.2 \%$ \\
\hline & in the country & $7.0 \%$ & $47.2 \%$ \\
\hline & average & 3.44 & 4.93 \\
\hline \multirow{6}{*}{ Time } & nothing & $12.2 \%$ & $1.3 \%$ \\
\hline & 1 hour & $12.1 \%$ & $3.5 \%$ \\
\hline & 1 hour $/$ month & $42.2 \%$ & $18.2 \%$ \\
\hline & 1 hour / week & $23.2 \%$ & $27.3 \%$ \\
\hline & More than 1 hour/ week & $10.4 \%$ & $49.8 \%$ \\
\hline & average & 3.07 & 4.21 \\
\hline
\end{tabular}

If the public and professionals had the opportunity to be involved in co-deciding (deciding about the most suitable design from the proposed alternatives for a new urban design), $86 \%$ of public and $97 \%$ of professionals would like to be involved. The same percentage of professionals $(97 \%)$ would like to have the option of co-designing public space in their hometown, and the percentage of members of the public with the same desire is in this case much smaller $(28 \%)$.

Table 1 shows, when, where and how much time the public and professionals want to devote to the planning and design of public urban spaces. Nearly half of all representatives of the profession want to be involved in the planning at the state level, and half of all members of the public mainly at the level of the city. Surprisingly, a large proportion of the public mainly wants to be involved in spatial planning at the level of cities, regions and countries (approx. 64\%). Only a small proportion of respondents never want to be involved in the planning process $(12 \%$ of the public and $1 \%$ of professionals). Contrary to professionals, the public wants to participate in the places that are closer to their home Table 2.

Professionals are willing to spend more time at designing public spaces than the public: nearly $50 \%$ of them are prepared to invest more than 1 hour per week. The public is willing to sacrifice only 1 hour per month for this purpose, which means that all methods, techniques and tools for their participation are designed so that the public does not consume too much time. A part of the public $(10 \%)$ is willing to invest more than 1 hour per week - these are interested members of the public who may be actively involved in the urban design process (Graph 2). 

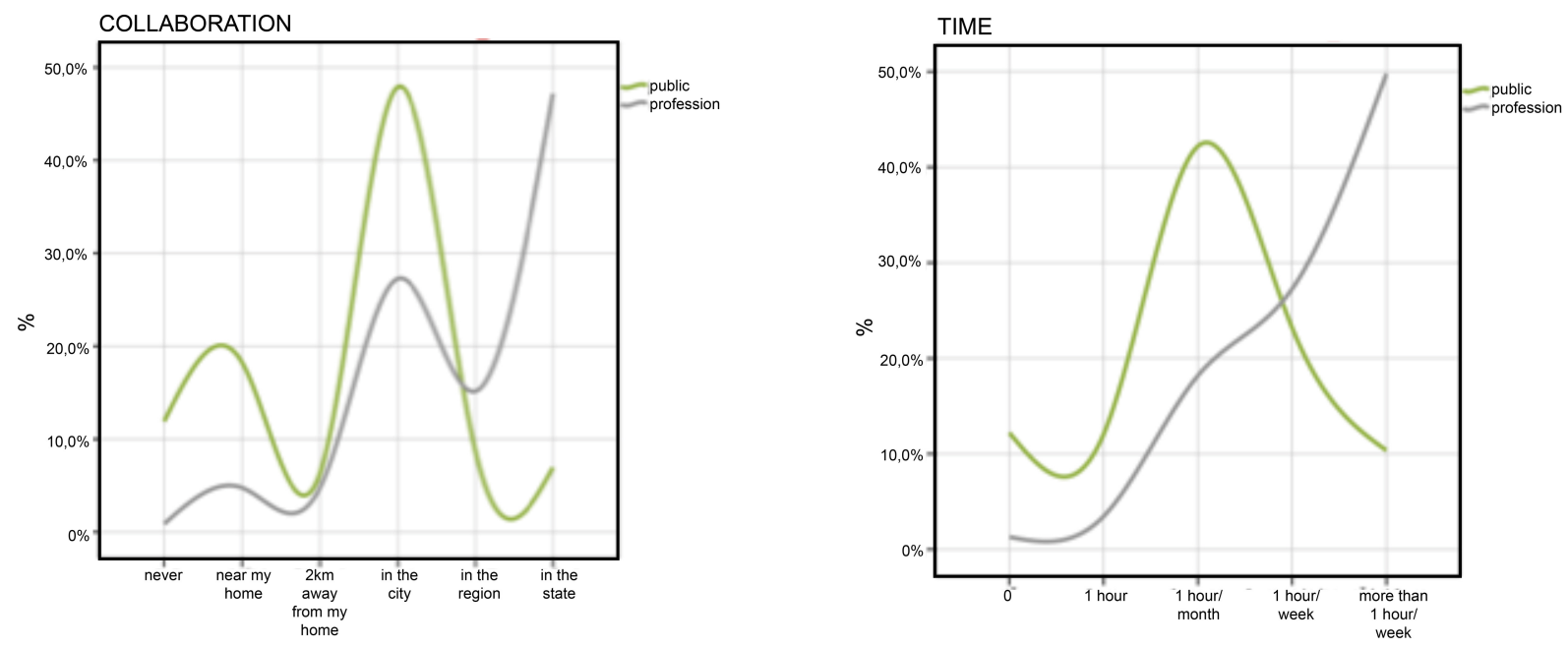

Graph 2. Comparison of the sentiments of the public and professionals relating to the area where they would like to participate in the urban design process (left) and the amount of time they would be willing to spend for this purpose (right).

Table 3. Desire of the public and professionals to be involved in the decision-making process, expressed in percentages.

\begin{tabular}{|c|c|c|c|}
\hline \multicolumn{2}{|c|}{} & Public & Profession \\
\hline \hline \multirow{3}{*}{ Possibility of decision-making } & yes & $85.6 \%$ & $97.0 \%$ \\
\cline { 2 - 4 } & no & $14.4 \%$ & $3.0 \%$ \\
\cline { 2 - 4 } & average (0=no, 1=yes) & 0.86 & 0.97 \\
\hline
\end{tabular}

If the public and professionals had a chance to be involved in the decision-making process (selection of the most suitable proposal from the proposed alternative solutions), $86 \%$ of the public and $97 \%$ of members of the profession would want to take part in the process (Table 3 ).

Interestingly, it seems that almost $50 \%$ of the representatives of the profession find public involvement in urban design very necessary, and the remaining half finds it necessary or desirable. The public sees the need for public involvement as more of a desirable than necessary activity $(41.7 \%$ of the public believe that public involvement in the planning process is only desirable, but not necessary) Graph $\mathbf{3}$.

We found out that most respondents preferred working either online or in person. Professionals put personal contact first (e.g. roundtables, workshops, meetings, etc.), as $82.3 \%$ of the representatives of the profession responded they liked this sort of collaboration best (among the public this percentage was significantly smaller, only $50.1 \%$ ). It is noticeable that online collaboration is a bit more popular among the public than among professionals: $64.9 \%$ of the public want to collaborate online, while the percentage among professionals is marginally smaller $(60.6 \%)$. Mobile applications appear to be a better tool for professionals (19.9\%) than for the public $(7.1 \%)$.

\section{(c) Semi-structured Interviews}

We carried out semi-structured interviews with eleven members of the public and ten interviews with representa- tives of the professional sphere. There was a wide range of individuals from both groups included in this process (regardless of age, gender, educational level and field). The interview was based on pre-prepared questions, while also leaving room for additional questions. Each interview lasted approximately 45 minutes (minimum 20 minutes, maximum 67 minutes). The information concerning the participants and their ways of thinking was collected through their active participation in semi-structured interviews, direct observation (emotional responses, skills exhibited when using tools), and through testing specific research questions (simplicity of the virtual world Terf and adequacy of tools for decisionmaking processes on the basis of pre-prepared tasks - respondents were given tasks, printed out on paper, and were invited to take some time to solve them).

Interviewees were given a printed table. We invited them to a walk through $3 \mathrm{D}$ models of the existing situation and through the three proposals for rearrangement of urban space, and the interviewees were asked whether they considered the experience of space (walk through the 3D model space) could improve the presentation of alternative solutions. Except for the two who remained unidentified, all felt that the experience of space could help present alternatives better. For a better presentation, the public would also like to upload photos of the real site. Professionals believe that the virtual world Terf is only a part of a wider process. They also believe that it is helpful if the users are, so to say, talked through the process of walking through the virtual space (a combination of visual presentations with sound). In addition to this, professionals mentioned that it would be good if Terf 


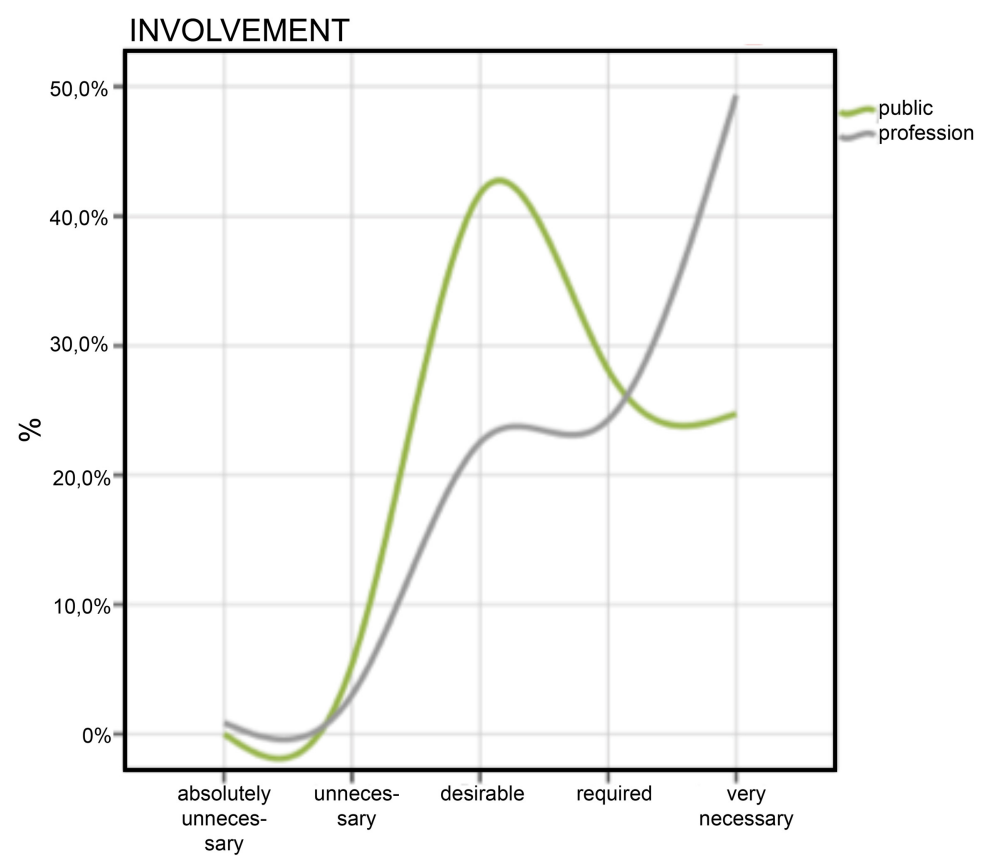

Graph 3. Comparison between the public and professionals with regard to the minimum number of alternative solutions that they would like to see, and with regard to the need to involve the public in the urban design process.
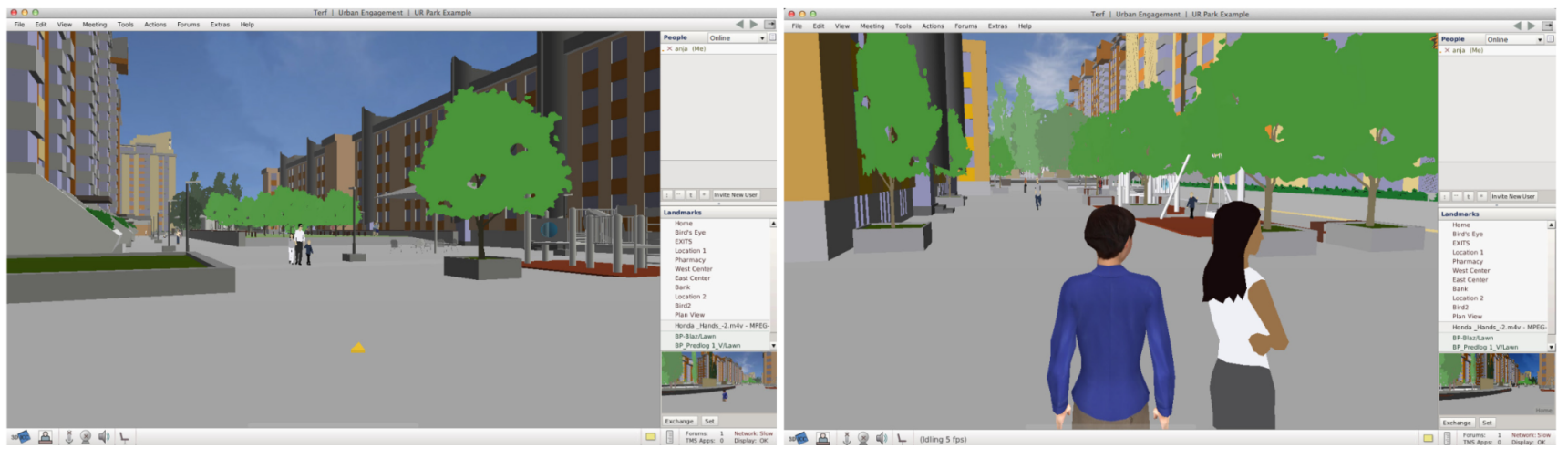

Fig. (4). Virtual world Terf, an interface for public participation in urban design: walk through different urban redesign proposals (virtual experience before real-life experience).

was combined with urban interventions in space: the public cannot imagine the final result until changes are actually seen in the area.

The majority of respondents (nine representatives of the public and seven representatives of the profession) finds Terf an appropriate tool for public involvement in urban design, a minority (one representative of the public and three representatives of the profession) finds it only partially applicable. One member of the public thinks that the tool is not suitable for public involvement. It can be seen that the public is more critical than professionals when evaluating the suitability of the tool. At this point, we would like to highlight some positive comments regarding the suitability of the tool: "Yes, very useful; enables a good walk through the space; the advantage of preset views, animation is suitable for people; very clear, you know exactly where you are on the platform; yes, because it is easy, many people might use it; yes because you can show different options; for a more reliable assessment; to gain a sense of space; for increasing motivation; like it because you get the feeling of space; positive, attractive, watchable, attractive". We did, however, analyze negative comments as well ("hard; people are afraid of the computer; does not provide a smooth walk through the space; just walking through the space is time-consuming; no textures; not for everyone; it is better than nothing; I would like to see floor plans; it is slow"), and the functions of the tool ("3D model is great, I would add images, I would add face-to-face meeting option, would like to add a large screen, now you are going to be happy to talk about it; videos would be very useful, I recommend a combination of film and sound; upgrade: to talk about the space in the room; improvement suggestions touch variants with the help of an urban mediator") (Fig. 4). 


\section{DISCUSSION AND CONCLUSION}

Based on the experiment and the qualitative and quantitative analyses, our conclusion is that public engagement activities at the early stages of an urban design process could have an influence on urban mobility. Public participation activities are changing the way residents are using public space, and they are also seen as an opportunity to educate the public about sustainable urban mobility (promoting cycling, walking etc.). Public participation is actually a long-life learning experience where different traditional and digital tools and methods are used to engage the public and professionals in urban design processes, and consequently build a community of people who will use and maintain a specific space.

\section{(a) Urban Experiment/ Intervention}

The concept of an urban experiment could be seen as a life-long learning opportunity allowing us to educate the public through involving them in urban activities. We asked them to solve the presented problem on their own, and offered them guidance and advice. Public spaces need users, and urban experiments are a good opportunity to involve people from the early stages of the design process onwards in order to teach them how to use space in a different way. This will eventually lead in creating a community of people who will also maintain the space in the future.

\section{(b) Survey}

Based on the survey, it can be concluded that both the public and professionals often share very similar opinions (see comparative graphs (1-3) in the previous section). Consequently, involving the public in the context of urban design is not always necessary; the public should not be involved in the decision-making process at any cost. Sometimes the opinion of professionals is sufficient. However, it is worth thinking carefully about when, where and how the public should indeed be included. It would be reasonable to include them at the first stages of urban design process when they can highlight the problem and opportunities for a specific area.

Much disagreement comes from ignorance and lack of understanding of the process of designing urban space - we can note here the need to educate the public about this issue. Based on the qualitative and quantitative analysis, we find that every public urban space has specific needs and requires special attention; we need to have in mind the needs of the public using a specific space. The presented results of the survey can help us understand how the public thinks. The survey results also help us conclude that the public wants to participate, co-design and be involved in the urban redesign process. Our task is to figure out when, where, how and to what extent this cooperation is most needed, effective and meaningful.

\section{(c) Semi-structured Interview}

By showing virtual world Terf to the public and professionals and interviewing them, we discovered that Terf is an appropriate digital tool for the public participation process. It is especially good for involving younger generations, as they usually do not have time for physical meetings. Combining traditional and digital tools is necessary.

Based on the presented research, the following benefits of Terf, a tool for public involvement in the planning process of urban space, can be observed: it promotes public awareness, brings urban design closer to the public (people can see what is possible, how to improve urban space and what are its alternative uses); it promotes avoidance of general dissatisfaction or disagreement with the final proposal; it could be used as an interface in lifelong learning processes: helps educate the public about urban space; it helps create a community that will begin to integrate and regulate its own space (no major interventions are required, the people who will use this space are needed, it is necessary to create a community that is itself responsible for the maintenance and appearance of urban space). Moreover, by using virtual world Terf also for company meetings, people would spend less time in their cars, thus making our streets less burdened with traffic.

\section{FINAL WORDS}

To conclude, public engagement has a huge influence on urban mobility, especially when traditional and digital methods and tools are combined. By involving people in urban redesign processes, we are educating them about urban space and the urban design process. To summarize, cities of the future could be seen as a combination of physical and digital networks: (1) program, urban equipment and users give life and appearance to urban space and influence urban mobility; (2) the public engagement from the early stages of urban design process onwards helps creating smart communities; and (3) the appropriate traditional and digital tools for public participation process could surely help in creating sustainable and smart cities, and influence urban mobility.

\section{CONFLICT OF INTEREST}

The authors confirm that this article content has no conflict of interest.

\section{ACKNOWLEDGEMENTS}

This research project was carried out in co-operation with the company 3D ICC Immersive Collaboration, and the Slovenian Research Agency (ARRS) supported it. The research was part of PhD studies at the University of Ljubljana, Faculty of Architecture. We would like to thank Julie LeMoine from the 3D ICC Immersice Collaboration for her assistance and for the opportunity to explore and work in Terf, an immersive virtual environment.

\section{REFERENCES}

[1] European Commission Urban Mobility 2014. Retrieved on December 10, 2014. Available from: http://ec.europa.eu/transport/themes/urban/urban_mobility/index_en.htm

[2] Action Plan on Urban Mobility - State of Play (report). European Commision, Directorate-general for mobility and transporta, Brussels, 2012. Retrieved on December 10, 2014. Available from: http://ec.europa.eu/transport/themes/urban/urban_mobility/doc/apu m_state_of_play.pdf 
[3] Audenhove FJ, Korniichuk O, Dauby L, Pourbaix J. The future of urban mobility 2.0: imperatives to shape extended mobility ecosystems of tomorrow. Arthur D.Little, UITP 2014. Retrieved on December 10, 2014. Available from: www.adl.com/FUM2.0

[4] Tsay S-P, Herrmann V. Rethinking urban mobility: sustainable policies for the century of the city. Washington DC: Carnegie Endowment for International Peace 2013.

[5] Study to support an impact assessment of the urban mobility package: activity 31 sustainable urban mobility plans (Final report). European Commision, DG Move 2013. Retrieved on December 10, 2014. Available from: http://ec.europa.eu/transport/themes/urban/studies/doc/2013-10-urban-mobility-package-activity-31.pdf

[6] Gehl J. URBACT USER - baseline study: changes and conflicts in using public spaces. USER, URBACT II, European Union 2013.

[7] Kéré Architecture 2014. Retrieved on December 10, 2014. Available from: http://www.kerearchitecture.com/about/

[8] Hunt JG. Forms of participation in urban redevelopment projects: the differing roles of public and stakeholder contributions to design decision making processes. In: Leeuwen JP, Timmermans HJP, Eds. Innovations in design and decision support systems in architecture and urban planning. Dordrecht, NL 2006.

[9] Rowley A, Gibson V, Ward C. Quality of urban design: a study of the involvement of private property decision-makers in urban design. London: Royal Institution of Chartered Surveyors and Department of the Environment 1996.

[10] Acland A. Dialogue by design: A handbook of public and stakeholder engagement. London: Dialogue by design 2012. Retrieved on December 10, 2014. Available from: http://designer.dialoguebydesign.net/docs/Dialogue_by_Design_Handbook.pdf

[11] Buscher V, Doody L, Webb M, Aoun C. Urban mobility in the smart city age. London: Schneider Electric, ARUP, The Climate Group 2014

[12] Al-kodmany K. Visualization tools and methods in community planning: from freehand sketches to virtual reality. J Planning Lit 2002;17(2). Retrieved on December 10, 2014. Available from: http://jpl.sagepub.com/cgi/content/abstract-/17/2/189

[13] Jones Q. Virtual-Communities, virtual settlements and cyberarchaeology: a theoretical outline. J Comp Med Commun 2006; 3(3). Retrieved on December 10, 2014. Available from: http://doi.wiley.com/10.1111/j.1083-6101.1997.tb-00075.x

[14] Jupp E. The feeling of participation: everyday spaces and urban change. Geoforum 2008; 39: 331-43.

[15] Lauwaert M. Playing the city: public participation in a contested suburban area. J Urban Technol 2009;16(2):143-68. Retrieved on December 10, 2014. Available from: http://www.informa- world.com/openurl?genre $=$ article $\&$ doi $=10.1080 / 106307309032786$ 11 \&magic $=$ crossref

[16] Bishop P, Williams L. The Temporary City. Oxon: Routledge 2012.

[17] Stevens Q, Ambler M. Europe's city beaches as post-fordist placemaking. J Urban Des 2010; 15(4): 515-37.

[18] Lehtovuori P. Temporary uses and place-based development. Theory and cases. Finland: Temper University of Technology 2013.

[19] Whyte WH. "Introduction", "The Life of Plazas", "Sitting Space", and "Sun, Wind, Trees, and Water." The Urban Design Reader. London and New York: Routledge 2007.

[20] For a safer city, dancing traffic lights 2014. Retrieved on December 10, 2014. Available from: http://int.smart.com/en/-en/index/smartcampaigns/whatareyoufor/for-a-safer-city.html

[21] A Streetcorner Serenade for the Public Plaza 2014. The New York Times: Art \& Design. Retrieved on December 10, 2014. Available from: http://www.nytimes.com/2013/06/02/arts/design/a-prescription-for-plazas-and-public-spaces.html?pagewanted=all\&_r=0

[22] New York City Dot 2014. Retrieved on December 10, 2014. Available from: http://www.nyc.gov/html/dot/html/home/home.shtml

[23] Project for Public Spaces 2014. Retrieved on December 10, 2014 Available from: http://www.pps.org/

[24] Kamfest 2014. Skupina Štajn. Retrieved on December 10, 2014 Available from: www.stajn.si

[25] Haller C. Cross-media public participation. Denver: Place Matters 2009.

[26] Hudson-smith A. Digitally distributed urban environments: The prospects for online planning. London: University College London 2003. Retrieved on December 10, 2014. Available from: www.casa.ucl.ac.uk/andy/

[27] Hanzl M. Information technology as a tool for public participation in urban planning: a review of experiments and potentials. Des Stud 2007; 28(3): 289-307. Retrieved on December 10, 2014. Available from: http://thane.wordpress.com/2007/08/26/publicð?participation-ð? in- $\partial$ ?web/

[28] Bainbridge WS. Online worlds: convergence of the real and the virtual. London: Springer 2010.

[29] Smith A, Dodge M, Doyle S. Visual communication in urban planning and urban design. London: UCL 1998.

[30] 3D Immersive collaboration consulting, immersive terf 2014. Retrieved on December 10, 2014. Available from: http://3dicc.com/

[31] Jutraž A. Sistem vizualnih digitalnih orodij za participacijo splošne javnosti pri prostorskem načrtovanju $=$ Visual digital system of tools for public participation in urban design. PhD Thesis. Faculty of arhitecture: University of Ljubljana 2013.

Received: June 10,2015

Revised: June 15, 2015

Accepted: June 15, 2015

(C) Jutraž and Zupančič; Licensee Bentham Open

This is an open access article licensed under the terms of the Creative Commons Attribution-Non-Commercial 4.0 International Public License (CC BY-NC 4.0) (https://creativecommons.org/licenses/by-nc/4.0/legalcode), which permits unrestricted, non-commercial use, distribution and reproduction in any medium, provided the work is properly cited. 